\title{
Covid-19 and long term conditions: what if you have cancer, diabetes, or chronic kidney disease?
}

\author{
Andy Extance
}

Exeter, UK

\section{Chronic kidney disease}

When the UK prime minister, live on national TV with the chief medical officer Chris Whitty, advised vulnerable patients-including those with chronic kidney disease-to minimise their social contact, it should have been a welcome surprise for Tess Harris, chief executive of the Polycystic Kidney Disease (PKD) charity. But recognition of this often unseen group provided no pleasure. Instead, it led to confusion.

Chronic kidney disease covers people with a wide range of symptom severity. Those at stage one usually have no obvious symptoms, or possibly blood in their urine. Those with stage five disease, like Harris, have lost nearly all kidney function. Yet Whitty's comments had people at stage one unnecessarily worried that they'd have to go into self-isolation, Harris told The BMJ. They were asking whether they should go to work, or let their children go to school, she explains. "That's been a big challenge - trying to interpret for patients."

Harris receives peritoneal dialysis at home. "It's life saving that I get my home dialysis fluids delivered along with everything else I need to stay safe," she explained. Because she has a tube protruding from her stomach, it's important for her to avoid infection, including maintaining good hand hygiene. Her deliveries come every two weeks, with her most recent arriving two days after Whitty's announcement. "Luckily, there was hand gel," she says. "In two weeks' time, however, I don't know." She has a routine appointment on 23 March but doesn't know if that's going ahead.

PKD is an inherited condition, meaning that several family members can have it, adding extra complications for self-isolation. As the disease advances, dialysis or a kidney transplantation becomes necessary. Harris notes that some living transplantations are being cancelled because of covid-19, in part because they would take up intensive care beds that will now be needed for patients with the virus. Her brother is currently waiting for a transplantation. "If they delay that for several months, he may well have to start emergency dialysis. That will require hospitalisation and surgery. It's bringing a lot of stress."

Meanwhile, Harris' younger sister received a transplantation six years ago, and now lives alone. She takes immunosuppressant drugs and had been practising social distancing to lower infection risk. "One PKD patient with a transplant told us they'd had a letter telling them to self-isolate. We're checking with others," she said. "I'm hoping that my sister gets support."

Overall, Harris sees communication as the most important factor for patients with chronic kidney disease. She noted that the international nephrology community is doing well at providing clinicians with the best guidance. "Getting it to filter down to the patients in their own language, however, is the hardest thing. It's challenging to explain the guidance to people who are scared, stressed, worried about work, worried about whether they're going to get paid, and if their children with PKD will be affected.”

\section{Diabetes}

On 17 March, Sarah Blake, who is doing a doctorate in digital health technology for vulnerable patient groups at the University of Bristol, took her four year old out of school. Blake has type 1 diabetes and is an at-risk patient who has been told to self-isolate for 12 weeks. She discovered and shared infographics on Twitter about how to manage diabetes while ill. Her advice covers points like the need to monitor and manage blood glucose levels, even if a person isn't eating, and never to stop taking diabetes drugs.

Yet Blake still has many worries. Not least, she is not sure how the virus impacts diabetes, how sick she needs to be to call a paramedic, what she should do if the emergency services are overwhelmed, or about access to food and medication now that she is isolated. "People living alone may be at increased risk, especially if extra demand means no access to online shopping," she said. "Free priority online groceries would be good for high risk groups."

Emma Cartwright, The BMJ's patient editor, also has type 1 diabetes and is now self-isolating. She said that the need for food and medication is especially great because diabetics treat low blood sugar with sweets or sugary juice. "I have heard of people who are struggling to get the supplies they might need or are being restricted to how much they can buy which causes large amounts of worry within the community," Cartwright said. Diabetics are advised not to stockpile, while deliveries of insulin 
pump supplies are delayed and ordering a month in advance is now advised.

This is typical of the confusion that is causing concern in the diabetes community, including whether people should be self-isolating, social distancing, or whether they should be at work. A lack of clarity over whether hospital appointments are happening is also "a huge concern."

"People don't want to burden the NHS with routine check-ups but also don't know when they might next be able to see someone if they don't attend," Cartwright says. The ideal solution, she says, would be to access health professionals through teleconferencing or phone calls.

\section{Cancer}

Currently, a quarter of calls to the support line run by UK cancer charity Macmillan Cancer Support are about covid-19, according to its chief medical officer Rosie Loftus. People living with cancer are more anxious than ever before, she told The BMJ.

While cancer services will continue despite the pandemic, in the NHS, less urgent activities may be curtailed, according to guidelines released on 17 March. ${ }^{1}$ It offers advice on how to prioritise treatment for patients with cancer. The guidelines are sensible, Karol Sikora, former clinical director for cancer services at Hammersmith Hospital in London, now chief medical officer at private oncology provider Rutherford Health, told The $B M J$. But he warned that the provisions it offers amount to rationing. "If you've got cancer, you're worried your treatment will stop," Sikora said, "We've not faced that in Britain before."

Loftus expressed a similar concern. "We recognise that these are exceptional circumstances for the NHS, but there must be a clear plan for continuing essential chemotherapy and radiotherapy treatment so that we don't see people with cancer missing out," she said.

Several classes of cancer treatment, including chemotherapy and immunotherapy, can suppress immune systems and make patients more susceptible to covid-19 infection. The UK government introduced stringent shielding guidelines for such "extremely vulnerable" people on 21 March. It has sent letters to those affected, advising them more strongly than previous guidance to stay at home at all times and avoid any face-to-face contact for a period of at least 12 weeks.

Sikora noted practical challenges, however. "Can we have a chemo suite just for coronavirus patients? The most serious challenge is getting patients to move around the system. Even if you can do a lot by telephone, many cancer centres are in big cities. If they shut down the cities, that would be a disaster for many patients with cancer."

Rationing of cancer care "is a reflection of the NHS being at full capacity," Sikora suggested. Covid-19 is now adding an extra burden, with a surge of patients and a reduced workforce as staff and their families are affected by the virus.

Consequently, Rutherford Health is offering its spare capacity to take on some of the cancer treatment burden. Sikora stressed that between his company and others there are around 20 private day care centres available. Rutherford Health's capacity would be available at the same prices and under the same contracts it has already agreed for NHS patients in Northumbria.

"If we thought imaginatively, we could alleviate the potential for interruption of cancer treatment," Sikora said. "Patients with cancer have to live with uncertainty as the disease unfolds. This is just another uncertainty - whether to have treatment, whether to delay, whether to stop, whether to reduce the dose. All these possibilities are very frightening for people."

\section{Biography}

Those needing long term medical care are among the groups hardest hit by coronavirus. Andy Extance asks how isolation and evolving procedures and systems are affecting patients

Competing interests: I have read and understood BMJ policy on declaration of interests and have no relevant interests to declare

1 Clinical guide for the management of cancer patients during the coronavirus pandemic. 17 March 2020. www.england.nhs.uk/coronavirus/wp-content/uploads/sites/52/2020/03/ Specialty-guide_Cancer-and-coronavirus_17-March.pdf

2 Guidance on shielding and protecting people defined on medical grounds as extremely vulnerable from COVID-19. 21 March 2020. www.gov.uk/government/publications/ guidance-on-shielding-and-protecting-extremely-vulnerable-persons-from-covid-19/ guidance-on-shielding-and-protecting-extremely-vulnerable-persons-from-covid-19.

Published by the BMJ Publishing Group Limited. For permission to use (where not already granted under a licence) please go to http://group.bmj.com/group/rights-licensing/ permissions 